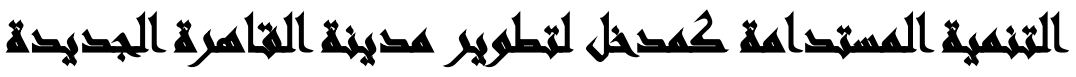

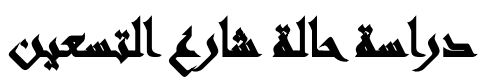

[V]

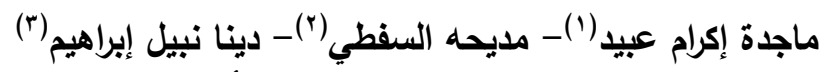

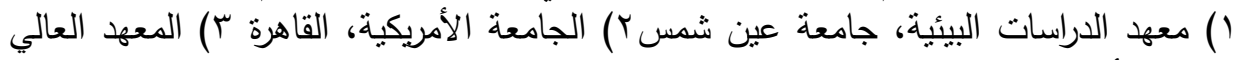
للإندسة بأكاديمية الثروق الثئن

\section{المستخلس}

لقد أستحوذ موضوع التتمية المستدامة علي اهتمام العالم على صعيد الساحة الاقتصادية

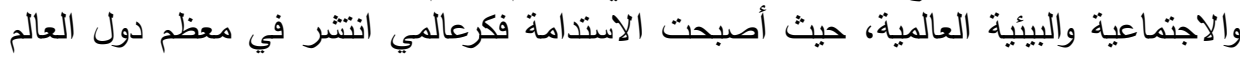

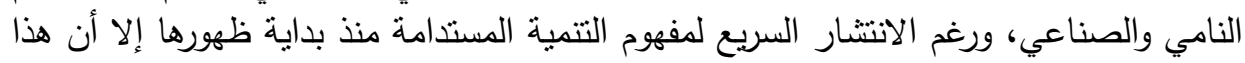

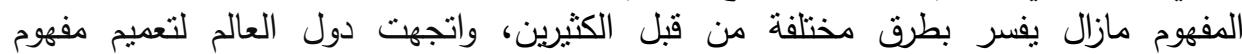
الاستدامةبسبب ندرة الموارد وارتفاع نسب التلوث، وتفاقم مشكلة.

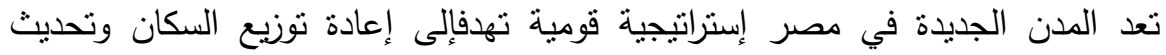

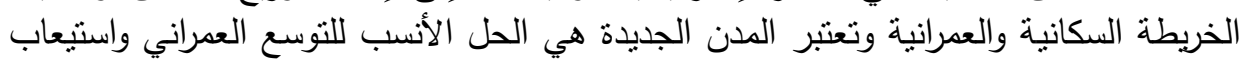

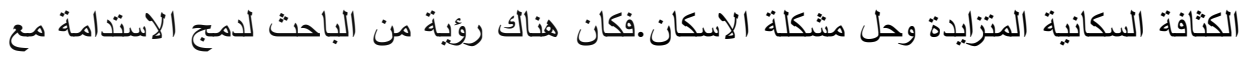

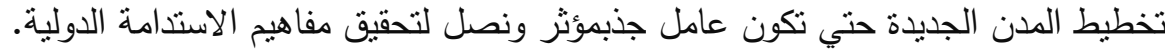

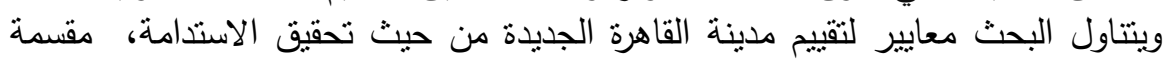

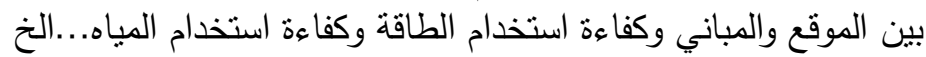

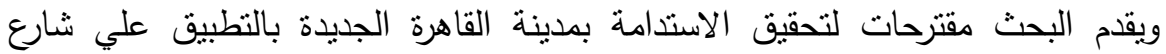

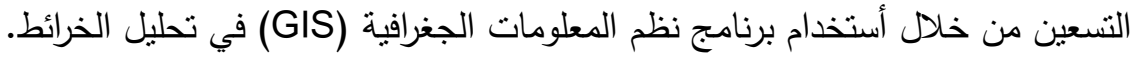
الكلمات الدالة: الاستدامة- كفاءة استخدام الطاقة - كفاءة استخدام المياه.

\section{Xaradl}

استعرض البحث معايير الاستدامة عند تخطيط المجتمعات العمرانية الجديدة وقد أصبح

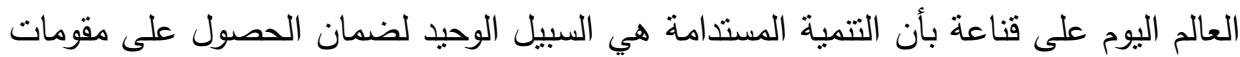
الحياة ومنطلبات الجودة من حيث الحفاظ علي الموارد وترشيد الطاقة في الحاضر والمستقبل.

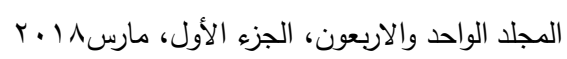


والاستدامة لها تعاريف متعددة أهمها ومايخدم البحث" انها محاولة لتوفير افضل النتائج للانسان والبيئة الطبيعية في الحاضر وفي المستقبل، أنها تتعلق بالجوانب الإتصادية والاجتماعية والمؤسسية والبيئية في المجتمع البثري والبيئة الطبيعية، أنها وسيلة لتنظيم الحضارة

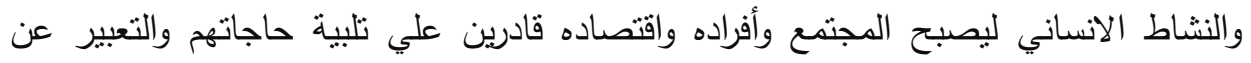

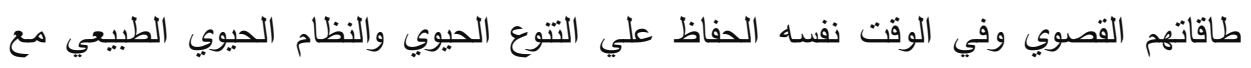
التخطيط لاستمرار في ذلك لمدي زمني بعيد". يعد نظام تقييم LEED للمجاورة السكنية هو أقرب الأنظمة لتقييم المدن الجديدة والاستدامة في

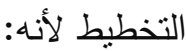
ا-نظام يقوم بتقدير وتقييم مشروعات حماية وتحسين الصحة العامةوالبيئة الطبيعية وجود

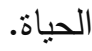
ب-نظام التقييم يشجع علي الممارسات الجيدة في مجالات النمو الذكي والعمران الجديد عن طريق: - تشجيع تصميم المجاورات السكنية واختبار مكانها مما يقلل استخدام المركبات.

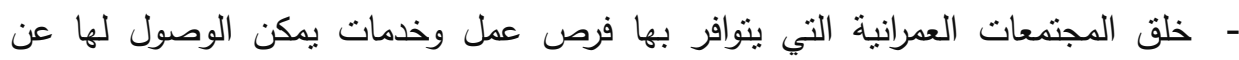

$$
\text { طريق المشي أو المواصلات العامة. }
$$
- - خلق شبكة من المباني الخضراء والبنية التحتية الخضراء لتحقيق كفاءة في استخدام المباه والطاقة.

\section{سبب اختيار شارع التسعين كلراسة حالة :}

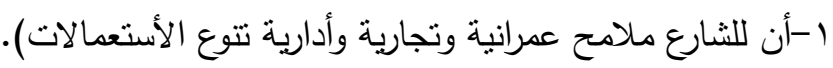

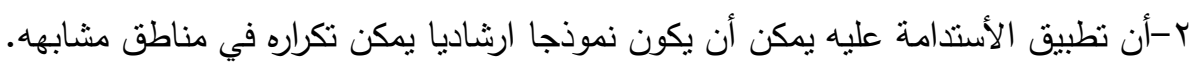




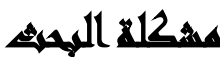

1-عدم وجود منهجية واضحة وتخطيط منظم عند تخطيط المدن الجديدة -شارع التسعين. r-افتقاد التخطيط لمفهوم الاستدامة والمشاركة المجنمعية.

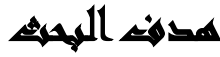

1-القاء الضوء علي معايير الاستدامة في التتمية العمرانية. r-مراجعة الاثشتراطات العمرانية للاستدامة ومدي تطبيقها في مدينة القاهرة الجديدة -شارع

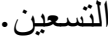
ب-وضع معاييرلتقييم الاستدامة في منطقة الدراسة.

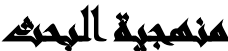

اتبع الباحث المنهج الاستقرائي والمنهج التحليلي في الجزء الميداني لتحقيق أهداف البحث.

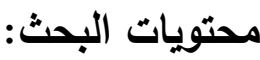

أولا: توصيف الموقع -المخطط العام-مراحل التنفيذ ثانيا: الدراسة الميدانية وإلتحليلية - ثم النتائج والتوصيات وصف الموقع: تقع مدينة القاهرة الجديدة علي منسوب أعلي من سطح البحر بحوالي • مب م وبذلك تتسم بجوها المعتدل طوال فصول السنه وهي تقع بالجانب الثرقي من القاهرة الكبري ملاصقة بالطريق الدائري وعلي طريق القطامية/ العين السخنة وطريق القاهرة السويس

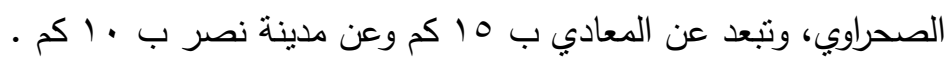




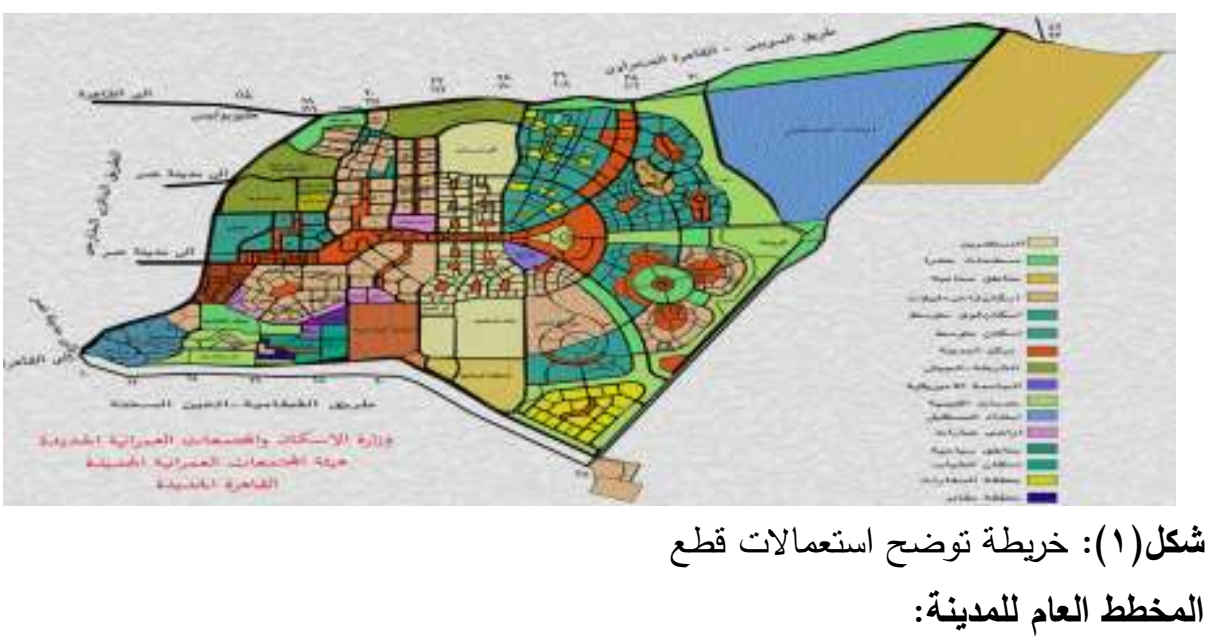

• تبلغ المساحة الأجمالية للمدينة • V ألف فدان منها Vج ألف فدان للكتلة العمرنية.

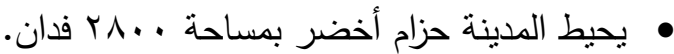

• تم تخطيط المدينة وتخصيص الأراضي ذات المساحات الصغيرة للافراد والكبيرة للشركات. • تعتبر المحاور الدائرية داخل المدينة كحاور ربط بين أجزائها المختلفة كما أنها تربط المراكز الثانوية للمناطق السكنية بالمراكز الأخري الموجودة بالتجمعات. • راعي التخطيط الدقة في تطبيق اثتراطات البناء الصحيحة للمباني فالاشتراطات الخاصة بالفيلات لا تتجاوز دور أرضي ودوربن متكررين اما اراضي العمارات فيسمح فيها بدور

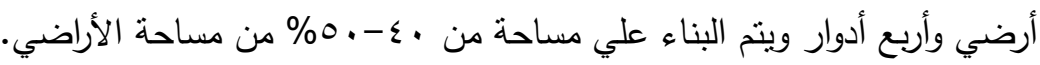

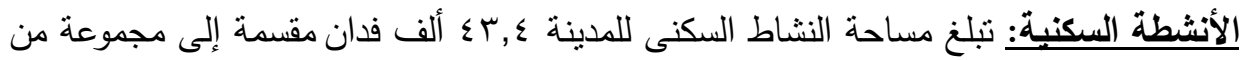
الأحياء نتنمل على جميع مستويات الإسكان (اقتصادي - منوسط - فوق منوسط - فاخر ) الأنثطة التجارية والإداريةة: حيث تم تخطيط مدينة القاهرة الجديدة علي أنيكون بها مراكز

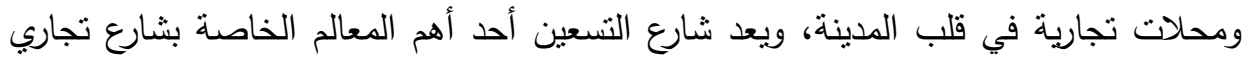
اداري حيث يشمل:عدد من البنوك والمطاعم والمولات. 
الأنشطة الترفيهية: - n

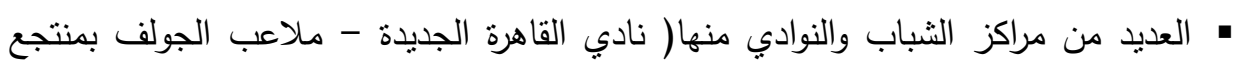

جولف القطامية -نادي الطيران - نادي الزهور -نادي بلاتينيوم - نادي وادي دجلة)

• مناطق خضراء مفتوحة (حديقة الطفل) والقرية الاوليمبية

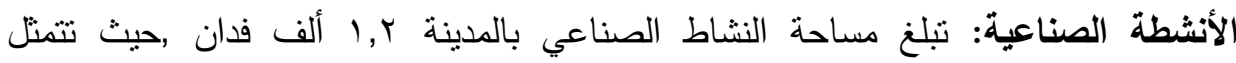

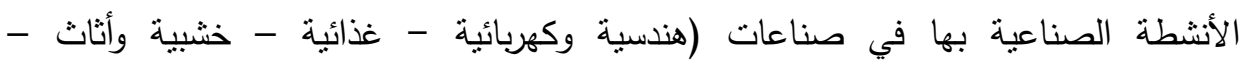
بلاستيكية- ورقية - غزل ونسيج - مواد بناء - معدنية وميكانيكية - كيماوية وأدوية - ملابس

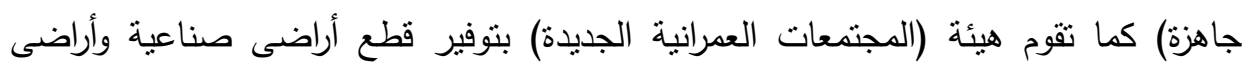
مخازن وورش صغيرة. الأبنية والأنشطة التعليمية: عدد كبير من الددارس الابندائية والثانوية، إضافة إلى مؤسسات

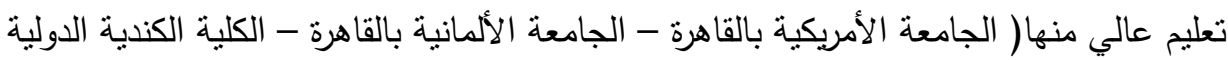

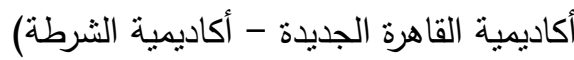

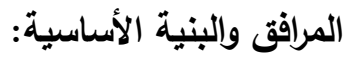
ا ــ المياه • تتغذى المدينة بمياه الثرب من خلال محطة تتقية مياهدينة العبوربكمية مياه . بr ألف

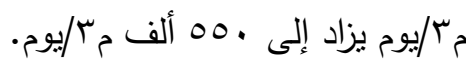

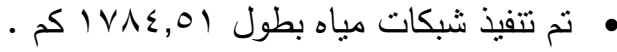

$$
\begin{aligned}
& \text { r. الصرف الصحي } \\
& \text { • تم تتفيذ ب محطات معالجة للصرف الصحي مدمجة بطاقة } 1 \text { آلاف مجّ/يوم. }
\end{aligned}
$$

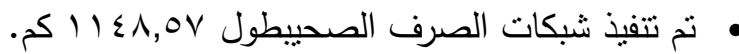

$$
\begin{aligned}
& \text { r. الكهياء }
\end{aligned}
$$

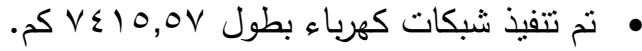


ـ ـ الطرق والاتصالات:

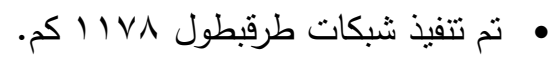

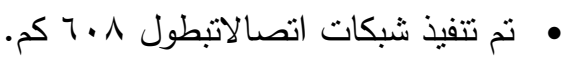

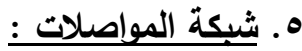

ترتبط المدينة بالمدن الأخرى عن طريق: • خطوط أتوبيس(هيئة النقل العامالقاهرة الكبرى) تربط المدينة بالعباسيةوميدان السيدة عائشة ميدان التحريروميدان رمسيس.

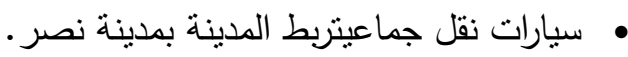
• سيارات تابعة لمدينة الرحابتربط المدينة بمترو أنفاق(سراي القبة - مدينة نصر )

1. البنية الاجتماعية للمنطقة: • الاستعمال المختلط للأراضي يتيح فرص عمل أكبر بجانب السكن وبالثالي تقليل الطاقة

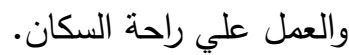
• المناطق المفتوحة بالمنطقة تعمل علي تقوية العلاقات بين السكان.-

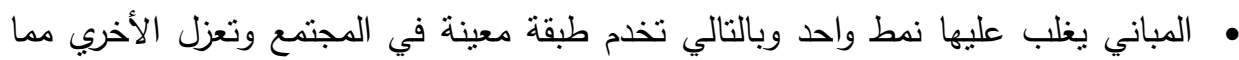
يؤثز سلبيا علي البيئة الاجتماعية.

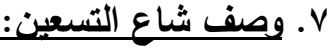
• من أكبر شوارع القاهرة الجديدة، يقع بطول المحور المركزي للمدينة، ويحوي مراكز مالية وادارية وأنشطة تجارية تخدم المدينة. ^. الدراسات التحليلية العمرانبة لمنطقة الدراسة: (الوضع الحالي):تم ذلك من خلال عمل رفع ميداني لمنطقة الدراسة وتحليل البيانات باستخدام برنامج نظم المعلومات الجغرافية (GIS) وشبكة|لطرق. وتم أعداد استمارة أستبيان وتم تحكيمها من خلال بعض المتخصصين في التخطيطوالتنمية ولقد شملت علي بيانات عامة وبيانات خاصة بالسكن ومفاهيم خاصة 
بالاستدامة ومعوقات الاستدامة، هذا ولقد تم اختيار عينة عشوائية للمترددين علي المنطقة شملت فئات مختلفة (سكان_زائرين_الذين يعملون بالمنطقة) وقسمت العينة لجزين: الأول:

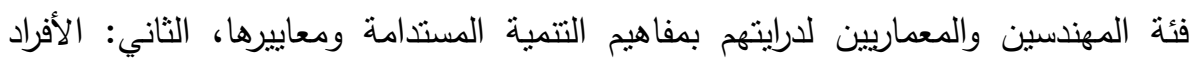
العاديين والذين يعملون بمؤهلات أخري مختلفة لقياس مدي معرفة الناس بنلك المفاهيم. والملامح الرئيسية للمنطقة يمكن تحليلها كالآتي: أولا:النسبيج العمراني :

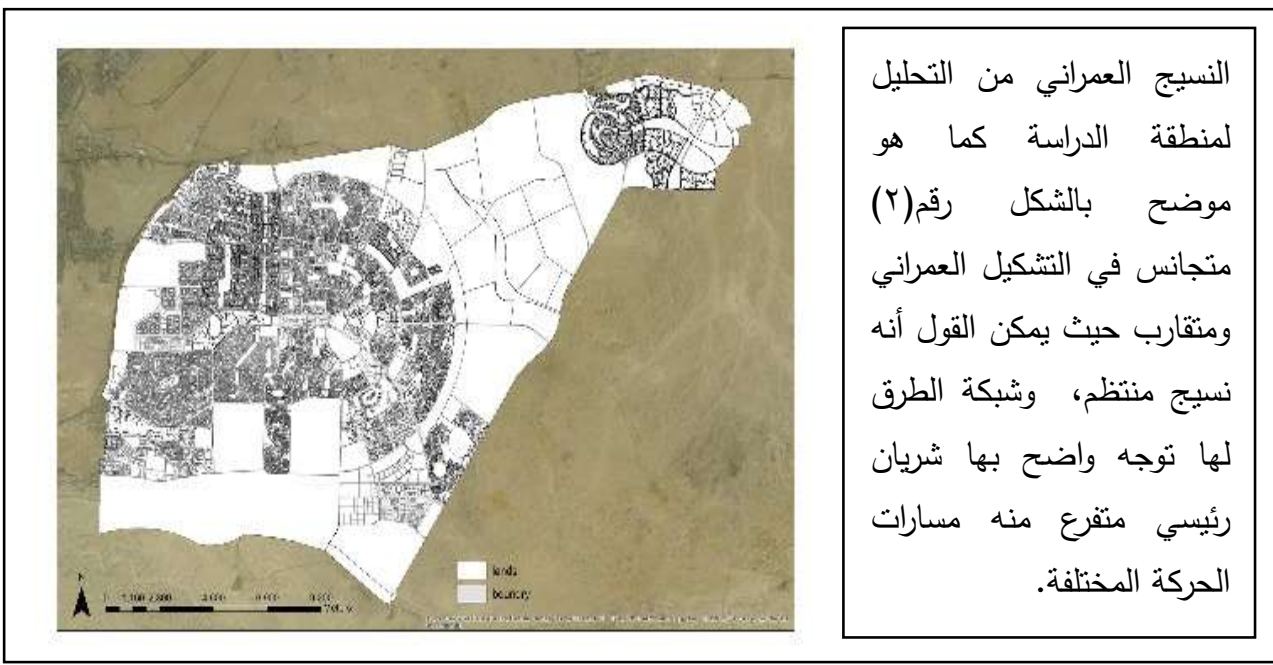
شكل(r): خريطة لمدينة القاهرة الجديدة 
ثانباً: ارتفاعات المباني:

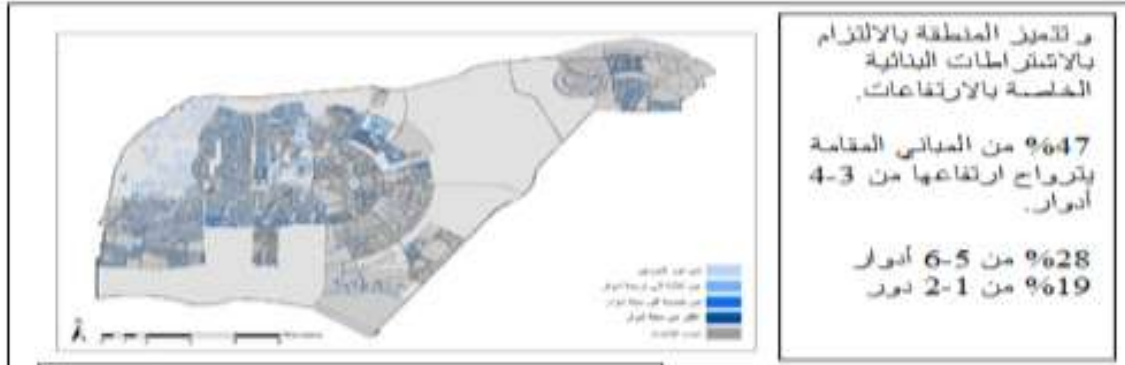

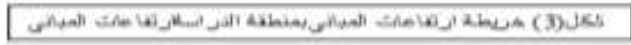

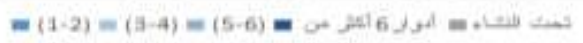

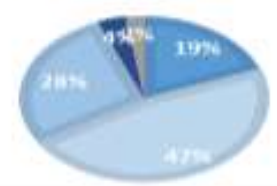

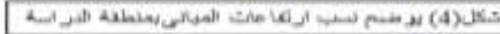

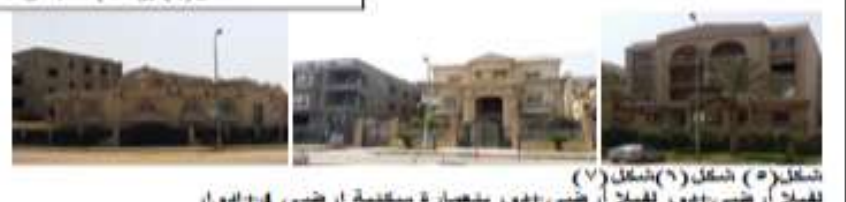

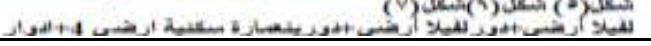

ثالثا :استعمالات المباني:

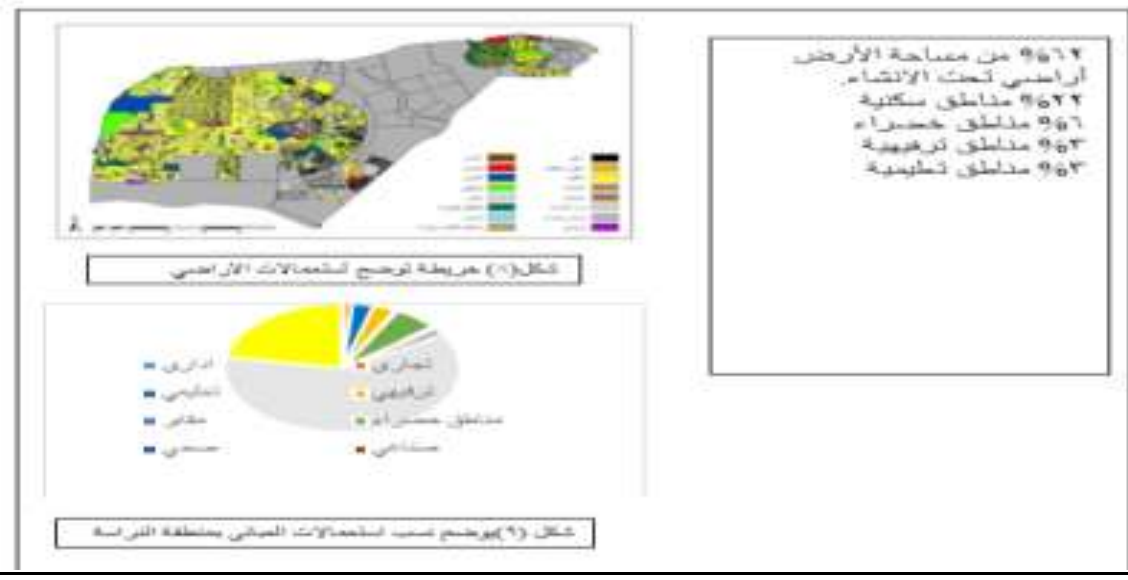

124

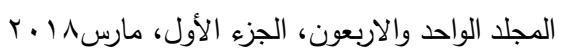


جدول رقم(1 ): يوضح تحليل لاراء المترددين علي المنطقة جدول معايير الاستدامة:

\begin{tabular}{|c|c|c|c|c|}
\hline نصبية & لم لمقق & تحقق & لا اعنه & 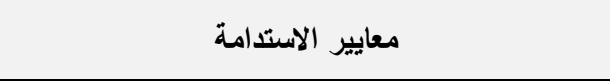 \\
\hline 44 & 14 & 34 & 16 & استخدام الالواح الثمسية في المبانى العامة \\
\hline 40 & 38 & 24 & 6 & استخدام الألواح الثشمسية في المنازل. \\
\hline 40 & 24 & 30 & 14 & استخدام الألواح الثمسية في الثشوارع وأعمدة الأنارة. \\
\hline 36 & 38 & 24 & 10 & تسخين المياه بالطاقة الشمسية(سخانات شمسية) \\
\hline 24 & 50 & 12 & 22 & استخدام توربينات الرياح لتوليد الطاقة. \\
\hline 34 & 40 & 18 & 16 & ترشيد استهلاك المياه في المبانى العامة. \\
\hline 34 & 32 & 30 & 12 & ترشيد استهلاك المياه في المنازل. \\
\hline 30 & 40 & 32 & 6 & ترشيد استهلاك المياه في الحدائق والمناطق الخضراء. \\
\hline 24 & 48 & 26 & 10 & إعادة تدوير المياه في المنشأت العامة. \\
\hline 28 & 44 & 28 & 8 & إعادة تدوير المياه في المنازل. \\
\hline 24 & 38 & 26 & 18 & إعادة تدوير المياه في الحدائق والمناطقالخضراء. \\
\hline 24 & 36 & 32 & 16 & الاستفادة من مياه الامطار \\
\hline 42 & 30 & 26 & 10 & فصل النفايات المنزلية \\
\hline 28 & 20 & 46 & 14 & إعادة تدوير القمامة واستخدامها مرة أخري. \\
\hline 34 & 46 & 20 & 8 & استخدام وسائل النقل المستدام \\
\hline 32 & 40 & 26 & 10 & وجود أرصفة وممرات مشاة مكشوفة ومظللة \\
\hline 24 & 46 & 32 & 6 & تو افور مسارات دراجات \\
\hline 42 & 20 & 42 & 4 & توافر أماكن انتظار سيارات \\
\hline 48 & 30 & 30 & 0 & توافر أماكن مظللة ومقاعد لانتظار المواصلات. \\
\hline 40 & 34 & 24 & 10 & أستخدام منتجات صديقة للبيئة \\
\hline 42 & 26 & 38 & 2 & أستخدام الوسائل الموفرة للطاقة \\
\hline 18 & 42 & 34 & 14 & اعادة استخدام الاكياس البلاستيك والعبواتباننواعها \\
\hline 32 & 36 & 24 & 16 & تخفيض استهلالك المواد بما في ذلك التعبئة والتظليف \\
\hline 38 & 32 & 24 & 14 & استخدام الألوان الفاتحة للاسقق لتعكس الأثشعة \\
\hline 38 & 42 & 20 & 8 & زراعة أسقق المنازل \\
\hline 42 & 38 & 16 & 12 & زراعة أسقق المبانى العامة \\
\hline 40 & 30 & 28 & 10 & استخدام النباتات المحلية في الحدائق \\
\hline 36 & 42 & 18 & 12 & استخدام مواد بناء صديقة للبيئة \\
\hline
\end{tabular}

يري المستخدمين أن استخدام الألواح الثمسية في المباني العامة تحقق بصورة نسبية

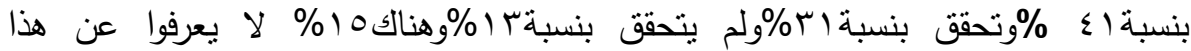

المعيارمن معايير الاستدامة.

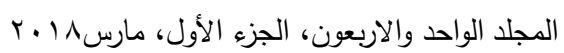


- يري المستخدمين أن ترشيد أستهلاك المياه في المباني العامة لم يتحقق بنسبة Vr\% وتحقق

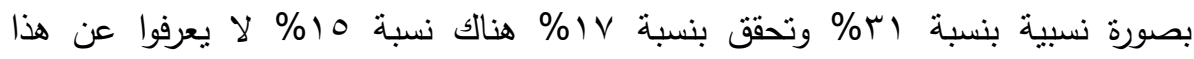
المعيارمن معايير الاستدامة.

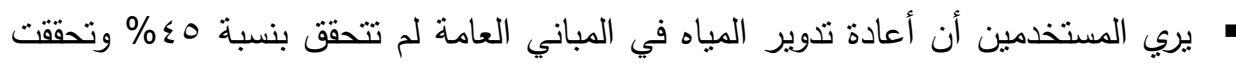

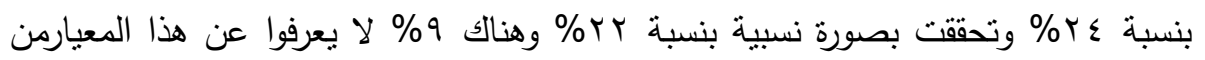
معايير الاستدامة. • بري المستخدمين أن فصل النفايات المنزلية تحقق بصورة نسبية بنسبة وب\% ولم يتحقق

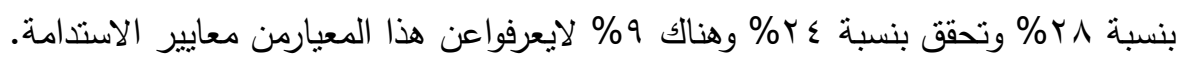

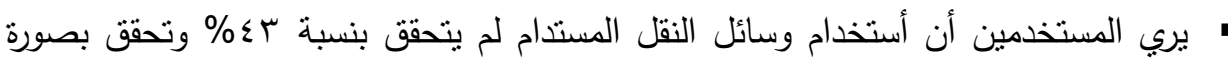

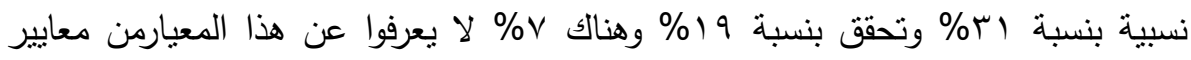
الاستدامة. 
جدول رقم(ץ): يوضح استمارة لتقييم مدي تحقيق الاستدامة بشارع التسعين

\begin{tabular}{|c|c|c|}
\hline & عناصر التقييم & \\
\hline & اختبار الموقع & \multirow{3}{*}{ 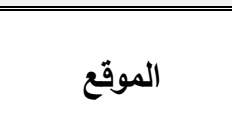 } \\
\hline & عملية النتيييد والبناء & \\
\hline & اعادة استخدام المباني & \\
\hline & شكل الكتلة ومسقطها الافقى & \multirow{3}{*}{ 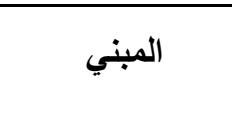 } \\
\hline & توجيه الكتلة & \\
\hline & معالجات الواجهات & \\
\hline & استخدام الالواح الثمسية في المبانى العامة & \multirow{4}{*}{ كفاءة استخدام } \\
\hline & استخدام الألواح الثمسية في المنازل. & \\
\hline & استخدام الألكاح الثمسبة في الثشوارع وأعمدة الأنارة. & \\
\hline & تسخين المباه بالطاقة الثمسية (وجود سخانات شمسية) & \\
\hline & تُشيد استهلالك المياه فى المبانى العامة. & \multirow{7}{*}{ كفاءة استخدام } \\
\hline & ترشيد استهالك المياه في المنازل. & \\
\hline & ترشيد استهلالك المياه في الحدائق والمناطق الخضراء. & \\
\hline & إعادة تدوير المياه في المنشأت العامة. & \\
\hline & إعادة تدوير المياه في المنازل. & \\
\hline & إعادة تدوير المياه في الحدائق والمناطق الخضراء. & \\
\hline & الاستفادة من مباه الامطار & \\
\hline & فصل النفايات المنزلية & \multirow{2}{*}{ اعادة التدوير } \\
\hline & إعادة تدوير القمامة واستخدامها مرة أخرى. & \\
\hline & استخداد وسائل النقل المستخام & النقل \\
\hline & وجود أرصفة وممرات مشاة مكثوفة ومظللة & \multirow{4}{*}{ الممرات واماكن } \\
\hline & تو افر مسارات دراجات & \\
\hline & توافر أماكن انتظار سبارات & \\
\hline & توافر أماكن مظللة ومقاعد لانتظار المواصلات. & \\
\hline & أستخدام منتجات صديقة للبيئة & \multirow{5}{*}{ المواد } \\
\hline & أستخدام الوسائل الموفرة للطاقة & \\
\hline & اعادة استخدام الاكياس البلاستيك والعبوات بأنواعها & \\
\hline & تخفيض استهلالك المواد بما في ذللك التنعبئة والتغليف & \\
\hline & استخدام مواد بناء صديقة للبيئة & \\
\hline & استخدام الألوان الفاتحة للاسقف لتعكس أَشعة الثشس & \multirow{4}{*}{ تقليل حرارة المبني } \\
\hline & زراعة أسقق المنازل & \\
\hline & زراعة أسقق المباني العامة & \\
\hline & استخدام النباتات المحلية في الحدائق & \\
\hline
\end{tabular}


مقترح لتطوير شارع التسعين وصولا ليكون مستداما: ( الكتلة والواجهات:

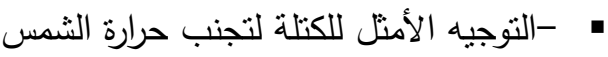
• - • - - - ل الالوانالفاتحة حيث تقوم بعكس الحرارة-استخدام زجاج مزدوج

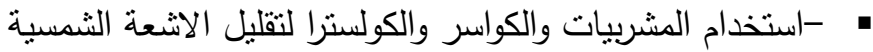

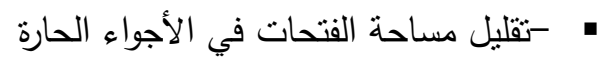
• - - زيادة مساحة الفتحات الجنوبية في الأجواء الباردة

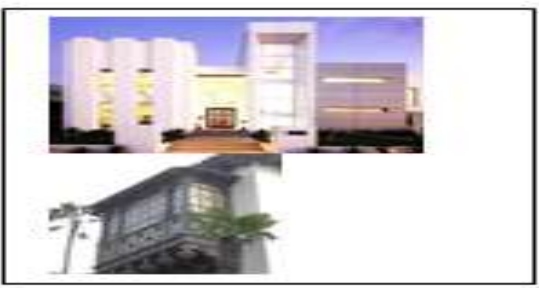

شكل(· · ): يوضح أفكار لنقليل دخول الحرارة للمبني

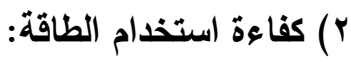
• تقعيل دور الخلايا الثمسية في توليد الطاقة بالمباني العامة والهنازل وأعمدة الانارة

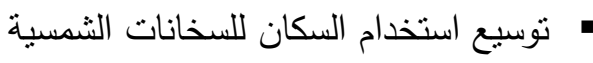

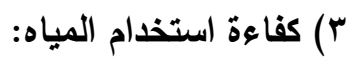
• استخدام أجزة تعمل بتدفق أقل للمياه

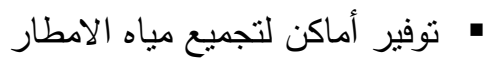

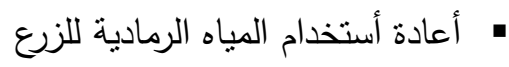
• استخدام نباتات قليلة الاحتياج للمياه 


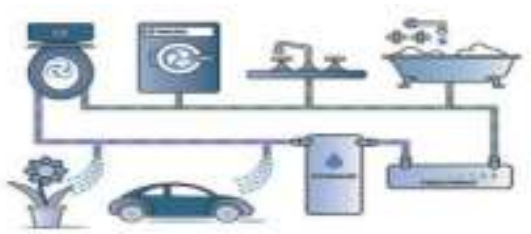

$$
\text { ؛ شكل( (1) ) : يوضح أعادة استخدام المياه الرمادية }
$$

• - - التتسيق مع جهات رسمية تكون مسئولة عن تجميع المواد القابلة لاعادة التدوير

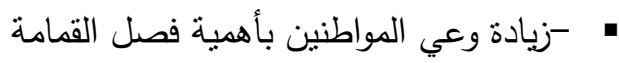
0) (النقل:

• - - - مير مسارات للاراجات حتي يتمكن المواطنين من استخدام وسائل نقل غير ملوثة للبيئة • - - - استخدام وسائل نقل تعتمد علي الوقود المتجدد الغير ملوث للبيئة

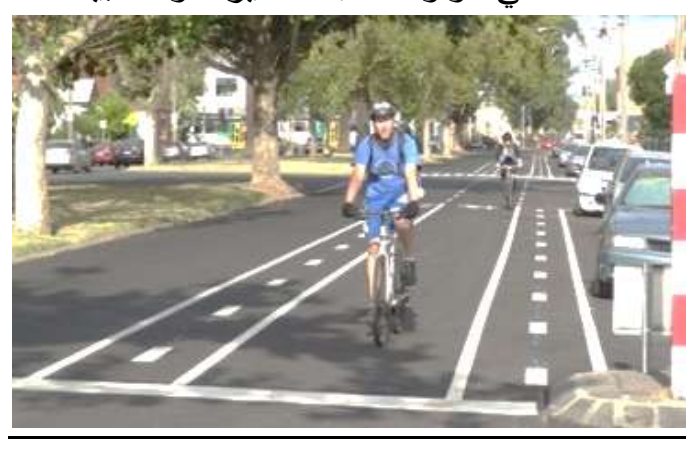

$$
\begin{aligned}
& \text { شكل( r I ): يوضح مسارات الدراجات } \\
& \text { ז) الطرق وأماكن انتظار السيارات: } \\
& \text { • التدرج في الخصوصية والاحتواء } \\
& \text { • وجود مسارات للاراجات } \\
& \text { • - توافر أماكن انتظار سيارات }
\end{aligned}
$$


V الرصيف وممرات المشاة: • - توفير ممرات أكثر والاهتمام بتغطيتها لتوفير ظلال وتحسين المناخ وتوفير راحة للمستخدمين • أن تكون من مواد ثتحمل الضغط

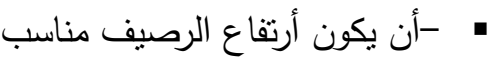
^) السدلالم والمنحدرات: • - توفير منحدرات ذوي الاحتياجات الخاصة وبالنسب القياسية • - - أن تكون مواد تشطيب المنحدرات لا تؤدي للانزلاق • - - -

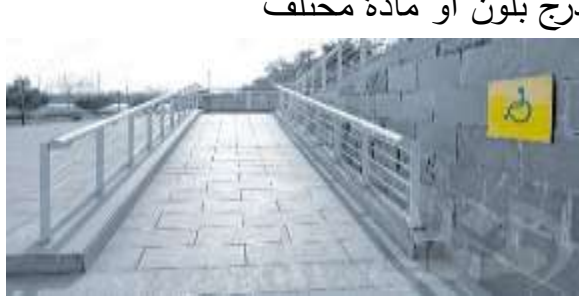

شكل( M I ): يوضح منحدرات ذوي الاحتياجات الخاصة 9 ) المقاعد: - توفير اماكن جلوس مريحة ومظللة وعلي مسافات مناسبة • توفير أماكن لانتظار المواصلات مظللة ومريحة هريه • أنتكون من مواد منوفرة بالبيئة • ت تماشي مع العناصر المحيطة • ل العتاج للصيانة بكثرة

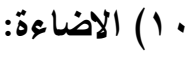
• أستخدام اللمبات الموفرة ووضع الواح شمسية بها • لاستفادة من الطاقة الثمسية • اختيار المكان المناسب لوضع وحدة الإضاءة 
• تثماشي وحدات الإضاءة مع طراز باقي العناصرالمحيطة

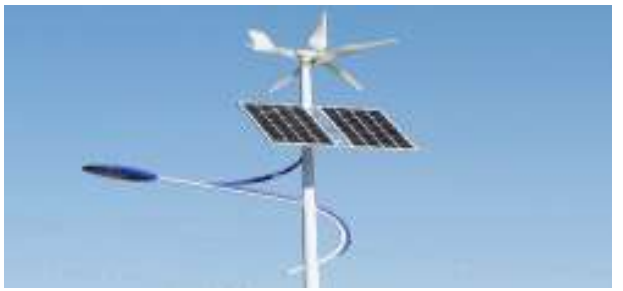

شكل(ع 1) : يوضح أعمدة الأنارة المزودة بخلايا شمسية (1) - (التشجير: • راعة نباتات محلية • التركيز علي الاشجار والنباتات قليلة الاستهلاك للماء • استخدام الاشجار لخلق اماكن، وترشيح الهواء من الاتربة

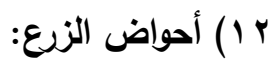
• تكون في موقع لا يؤثر علي حركة المشاة - الاعتماد علي الاحواض الكبيرة لحماية الزرع من الجفاف • أن تكون من مواد تتميز بسهولة الصبانة ب ا ) الإعلانات والعلامات الارشادية • أن تكون من مواد سهلة الصيانة والتظيف الهيف - تنتاسب في الشكل والحجم والمكان مع العناصر المحيطة ع 1) صناديق القمامة:

• مقسمة بطريقة تسمح بإعادة تدويرها بسهولة

• مصمة بشكل لايسمح بظهور القمامة منها • لاتزبد المسافة بين أماكن الصناديق عن • م 


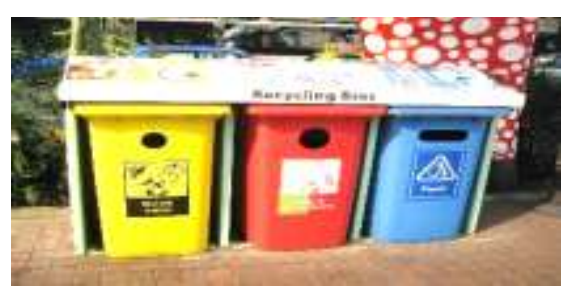

شكل(0 1 ): يوضح صناديق القمامة المخصصة لإعادة التدوير

: 10

• توفير المسطحات المائية حيث تعمل المسطحات المائية علي ثبريد الهواء

- تعطي شعور بالسرور والتواصل مع البيئة الطبيعية

צ 1 ) المواد المستخدمة

• مواد لا تؤثز علي الصحة

• مواد متوفرة بالبيئة المحيطة لمولئ ل

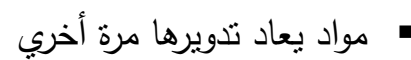

• استخدام العبوات والأكياس التي يعاد استخدمها مرة أخري موري

• أستخدام مواد صديقة للبيئة (قليلة الانبعاثات- قريبة من الموقع - يعاد استخدمها)

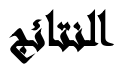

• تثميز المنطقة بالالتزام بالاشتراطات البنائية الخاصة بالارتفاعات.

• ومن تحليل خريطة الارتقاعات نجد ان نسبة \&\&\% من أجمالي المباني القائمة يتراوح

$$
\text { ارتفاعها من r-ع أدوار }
$$

• بدراسة خط السماء لثارع التسعين نجد أنه قريب من الاستمرارية لوجود اشتراطات محددة

لارتفاعات المباني السكنية، علي عكس الجانب الاخر من الثارع حيث البنوك والمحلات التجارية والثركات وهي منطقة الأنثطة التجارية نجد عدم استمراية واخلال بخط السماء

$$
\text { وتباين في الارتفاعات وإن كانت بصورة غير منتافرة. }
$$


• آراء المستخدمين أن المعوقات الرئيسية لتطبيق معايير الاستدامة بمدينة القاهرة الجديدة-

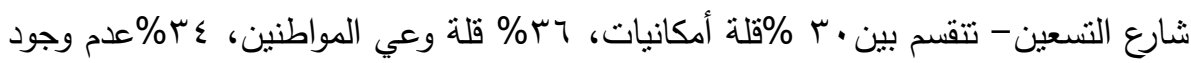
تتسيق بين المواطنين والدولة.

• يري المستخدمين أن استخدام الألواح الثمسية في المباني العامة تحقق بصورة نسبية

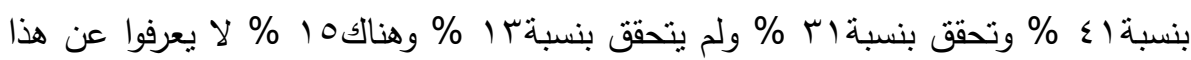
المعيار من معايير الاستدامة.

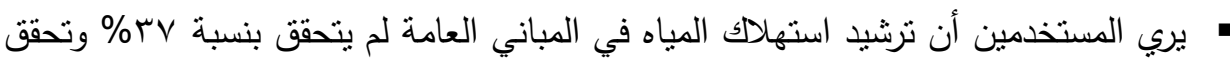

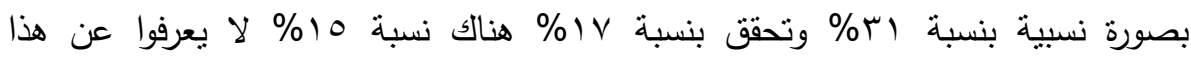
المعيارمن معايير الاستدامة.

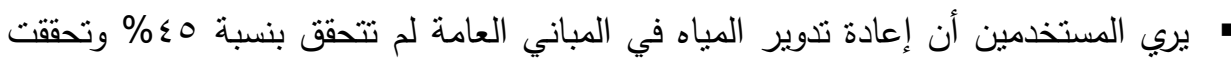

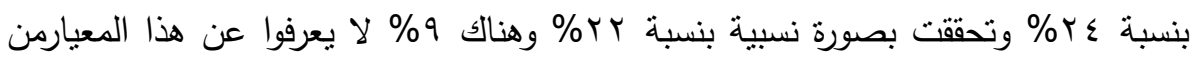
معايير الاستدامة • يري المستخدمين أن فصل النفايات المنزلية تحقق بصورة نسبية بنسبة وبه ولم يتحقق

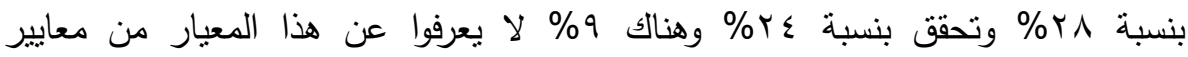
الاستدامة. يري المستخدمين أن استخدام وسائل النقل المستدام لم يتحقق بنسبة بـ\% وتحقق بصورة

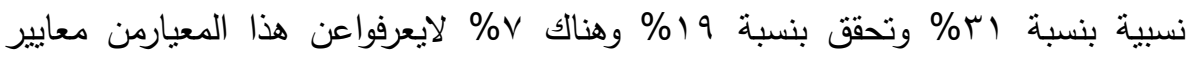
الاستدامة.

\section{اللزوسياني}

\section{أ) علي مستوي الاولة:}

() توفير امنيازات للمباني التي تحقق معدلات الاستدامة المطلوبة تثجيعا من الدولة لتعميم تلك الأفكار

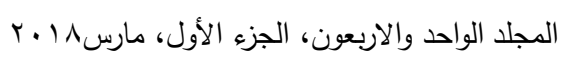


r) تفعيل دور المؤسسات التي تهتم بالامور المتعلقة بالاستدامة ( مجموعات الثباب أصحاب

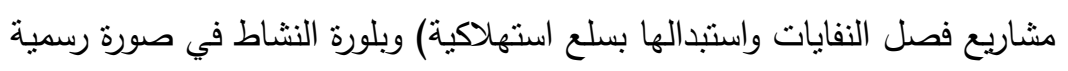
r) أعمال التتبيد والبناء والتأكد من تحقيق معايير الاستدامة ب) علي مستوي المخططين: () مراعاة معايير الاستدامة عند تخطيط المدن

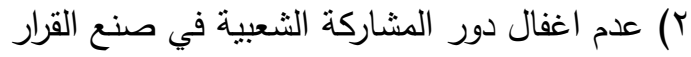

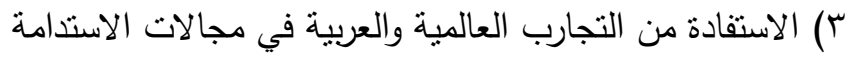
ج) علي مستوي المستخدمين: ( ) الاستخدام الامثل للموارد وعدم إهدارها. r) تفعيل الأنشطة الني تساهم في تحقيق الاستدامة (استخدام الدراجات. فصل النفايات.استخدام

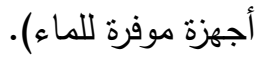

\section{sall}

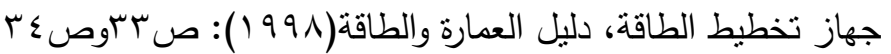

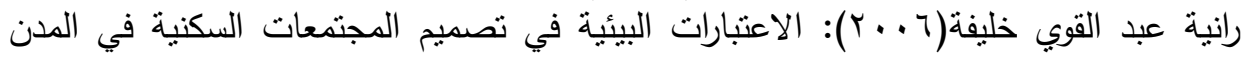

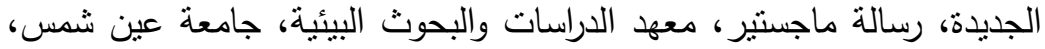

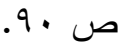

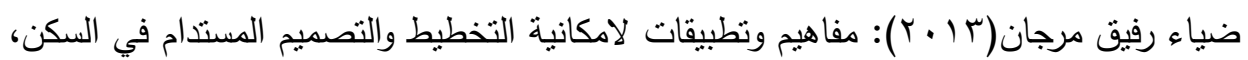

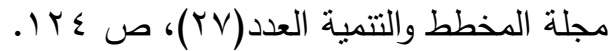

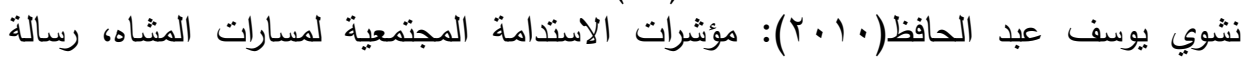

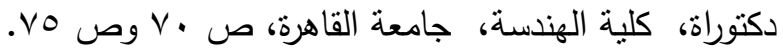

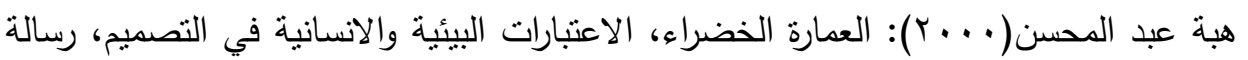

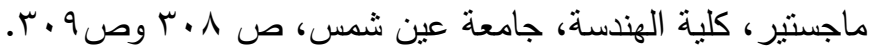


ماجدة إكرام عبيد وآخرون

\title{
EVALUATION OF NEW CAIRO CITY EXPERIENCE \\ ACCORDING TO THE SUSTAINABLE DEVELOPMENT STANDARDS
}

Ebead, Magda, E. ${ }^{(1)}$; El Safty, Madiha, ${ }^{(2)}$ and Ibrahim, Dina, N. ${ }^{(3)}$ 1) Institute of Environmental Studies, Ain Shams University 2) The American University In Cairo 3) Higher Institute of Engineering, Shorouk Academy

\begin{abstract}
The theme of sustainable development has taken on the world's attention in the global economic, social and environmental arena, where sustainability has become an intellectual spread in most of the developing and industrial countries. Despite the rapid spread of sustainable development since its inception, Countries of the world to mainstream the concept of sustainability because of the scarcity of resources and high rates of pollution, and the aggravation of the problem.

The new cities in Egypt are a national strategy aimed at redistributing the population and modernizing the population and urban map. The new cities are considered the most suitable solution for urban expansion, absorbing the increasing population density and solving the housing problem.

The research deals with criteria for assessing the new city of Cairo in terms of achieving sustainability, divided between location and buildings, energy efficiency, water efficiency, etc.

The research presents proposals for achieving sustainability in the new city of Cairo by applying on the 90th Street through the use of GIS in map analysis.
\end{abstract}

Keywords: sustainability - energy efficiency - water efficiency.

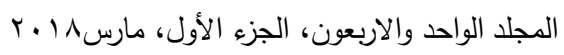

